The Digital Object Identifier - DOI: 10.37952/ROI-jbc-01/19-58-5-70

Submitted on May 31, 2019.

\title{
Azo-substituted ethoxyacridine - reagents for the extraction-photometric determination of gallium
}

\author{
(C) Namig I. Ismailov, ${ }^{+}$and Sevinj N. Osmanova \\ Institute of Catalysis and Inorganic Chemistry Named after Acad. M.F. Naghiyev of Azerbaijan National \\ Academy of Sciences. H. Javid Ave. 113. Baku, AZ1143. Azerbaijan Republic. \\ E-mail: o.sevinc1985@rambler.ru
}

*Supervising author; ${ }^{+}$Corresponding author

Keywords: azo-ethoxyacridines, extraction-photometric analysis, determination of gallium.

\begin{abstract}
The associates of halide (chloride) complexes of gallim azo-substituted ethoxyacridine have been studied by spectrophotometric method. It has been found that the associates are well extracted with a mixture of dichloroethane-acetone (3:2). The optimum volume of aqueous and organic phase is equal to $5 \mathrm{ml}$. The molar ratio of the components in the extractable compounds was studied by the methods of isomolar series, equilibrium shift and a straight line. It was found that gallium chloride associated with azo-ethoxyacridines (AE) in a ratio of 1:1.

It was studied formation and extraction of associates of gallium chloride with AEADPA (2-ethoxy-6-(4$N, N$-dipropylphenylazo)-9-aminoacridine) and AEAN (2-ethoxy-6-(2-hydroxynaphthylazo)-9aminoacridine). The maxima of light absorption of gallium chloride with AEADPA is observed at $520 \mathrm{~nm}$, and the AEAN at $510 \mathrm{~nm}$. The light absorption of the extracts of associates coincides with the absorption maxima of azoethoxyacridines, which indicates the electrostatic character of the interaction and the formation of complexes.

Study of the effect of foreign ions on the accuracy of the determination of gallium with azo-substituted ethoxyacridine showed that the number of ions does not interfere (in parentheses are multiple relationships to gallium ions); $\mathrm{Zn}^{2+}(2000), \mathrm{Ni}^{\mathrm{II}}(1500), \mathrm{Cu}^{\mathrm{II}}(2500), \mathrm{Co}^{\mathrm{II}}(1400), \mathrm{Cr}{ }^{\mathrm{III}}(1100), \mathrm{Pb}^{\mathrm{I}}(2250), \mathrm{Al}^{3+}(1600), \mathrm{Cd}^{2+}(700)$, $\mathrm{Fe}^{\mathrm{II}}(1050), \mathrm{Re}^{\mathrm{VII}}(500), \mathrm{Pd}^{\mathrm{III}}(1200), \mathrm{Tl}(2500)$. Number of ions interfered the determination: $\mathrm{Te}^{\mathrm{IV}}(1), \mathrm{Fe}^{\mathrm{III}}(1)$, $\mathrm{Au}^{\mathrm{III}}(1), \mathrm{Sb}^{\mathrm{V}}(1), \mathrm{Tl}^{\mathrm{III}}(1), \mathrm{Se}^{\mathrm{IV}}(3)$.

The physico-chemical and analytical characteristics of the azo-substituted ethoxyacridines and their ionic associates with chloride gallium acidic complexes $\left(\lambda_{\max } \varepsilon, \beta \mathrm{kD}, \mathrm{D}, \mathrm{R} \%\right)$ were determined. It was shown that chlorogallium compounds with azo-substituted ethoxyacridines are ionic associates, the molar ratios of the components in which are:
\end{abstract}

$$
\left[\mathrm{Ga}^{3+}\right]:\left[\mathrm{Cl}^{-}\right]: \mathrm{R}^{+}=1: 4: 1 .
$$

\section{References}

[1] A.T. Plipenko, M.M. Tananaiko. J. Anal. Chem. 1973. Vol.28. No.9. P.745-749. (russian)

[2] N.I. Ismailov, I.K. Huseynov. Azerb. Chem. Journ. 1980. No.4. P.113-117. (russian)

[3] N.I. Ismailov. Journ. Chem. Prob. 2003. Vol.12. No.2. P.13-22. (russian)

[4] N.I. Ismailov, S.N. Osmanova, M.V. Mammadova. Extraction-photometric determination of indium with azo-substituted ethoxyacridine. Butlerov Communications. 2018. Vol.53. No.2. P.100-103. DOI: 10.37952/ROI-jbc-01/18-53-2-100

[5] R. Solanker, S.M. Khopkar. Indian I Chem. 1973. Vol.11. No.5. P.485-490.

[6] C. Sonchez- Pedreno, M. Hernandez Cordoba. Afinidad. 1985. Vol.42. No.389. P.399-403.

[7] A.M. Dimov, A.P. Savostin. Analitical chemistry of gallium. Science. 1968. 256p. (russian)

[8] G.L. Shlefer. Complexation in solutions. Leningrad: Chemistry. 1964. 379p. (russian)

[9] M.I. Bulatov, I.P. Kalinkin. Practical guidance on photocolorimetric and spectrophotometric methods of analysis. Leningrad: Chemistry. 1976. 376p. (russian)

[10] E.K. Suslennikova. Guide to the preparation of titrated solutions. Leningrad: Chemistry. 1973. 184p. (russian) 